\title{
The effects of new ways of work in the Netherlands: national data and a case study
}

\author{
P. Vink ${ }^{\mathrm{a}}$, M. Blok ${ }^{\mathrm{b}}$, M. Formanoy ${ }^{\mathrm{b}}$, E. de Korte ${ }^{\mathrm{a} / \mathrm{b}}$ and L. Groenesteijn ${ }^{\mathrm{a} / \mathrm{b}}$ \\ ${ }^{a}$ Faculty of Industrial Design Engineering, Delft University of Technology, Landbergstraat 15, 2628 CE Delft, \\ The Netherlands. \\ ${ }^{\mathrm{b}}$ TNO, P.O. Box 718, 2130 AS Hoofddorp, The Netherlands
}

\begin{abstract}
In 2010 15.2\% of the work force in the Netherlands works with a computer at another location than at the office or at the clients' location. $27 \%$ of the Dutch working population is not satisfied about the possibility to work at home and $18 \%$ is not satisfied on the possibility to plan your own working time. The case control study affirms what has been reported as effects of new ways of work: the experienced productivity by communication and the representativeness of the office interior are improved and attention is needed for workers that need concentration space and need to personalize their work environment. In implementing new ways of work these issues need attention.
\end{abstract}

Keywords: new ways of work, office interior, telework, work at home, flexible working time

\section{Introduction}

New information and communication technologies like teleconferencing and internet facilitate new ways of work [5]. It provides new alternatives for where, when and how to do the work and reduces the necessity of coming to the office. This new way of work is promoted by many consultants (including ergonomists), suppliers and information and communication advisors causing a more widespread introduction. However, the effects on productivity and health (defined as a state of physical, social and mental wellbeing) are only superficially studied. In the Netherlands many companies are working on the implementation of new ways of work. However, before implementation of this new way of work on a larger scale, it is important to know more about the positive effects and the side effects of this new way of work. Therefore, in this paper more information on effects is gathered. Data on macro level (national data) will be presented as well as on micro level (how do end users experience the new way of working compared with the traditional way). Not all aspects of new ways of work can be studied of course. The new way of work is not only 'distant work' or a new office interior, but also freedom in working times, other management etcetera. In this study the focus is on how widespread teleworking and freedom to determine working times is implemented in the Netherlands. Teleworking is seen in this paper as working with a computer at another location than at the office or at the clients location.

Additionally, one case control study is described in which the intervention is "implementing new ways of work". This paper consists of two research question of this paper is:

1. How many workers in the Netherlands are "teleworking" in 2010 and is there a need for more freedom in choosing working times and to work at home?

2. What are effects on work satisfaction, health, productivity, creativity, representativeness and use of the office space of introducing the new way of work?

\section{Method}

To answer the research questions two separate studies are done. Secondary analysis was done on the data of the Dutch national survey on work and working conditions to find out how many employees work away from the office (=telework). Every year TNO studies the work and working conditions in the Netherlands using a questionnaire. In this survey a representative sample out of the Dutch working population 
of 7,094,207 persons is taken [4]. From previous years we know that the response rate is between 30 and $35 \%$. Therefore a sample of 80,000 persons was taken in 2010. The sample was equally distributed over the classes: gender, age, sector of work and region. The questionnaire consisted of many aspects of work. In this paper only the results regarding new ways of work were considered. These questions concern: hours of VDU work, if workers like to do their job at another place than the office, whether they think it is important to define the working time themselves and to work at home and whether they are satisfied on the possibility at their work to define the working time themselves and to work at home. It is tested whether a subpopulation has a different value than the total by using Cohen's $d$ [2]. If Cohen's $d \geq$ 0.20 than it is reported in the table by "higher" and "lower" showing that it is higher or lower than the total population.

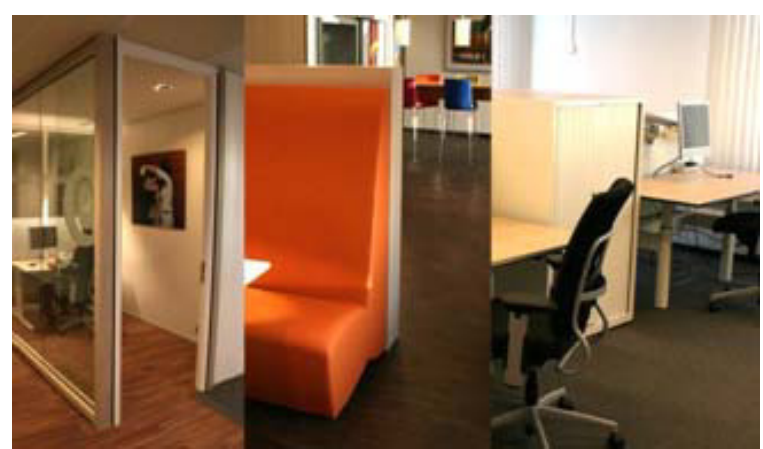

Fig 1. An impression of the new interior in the case control study.

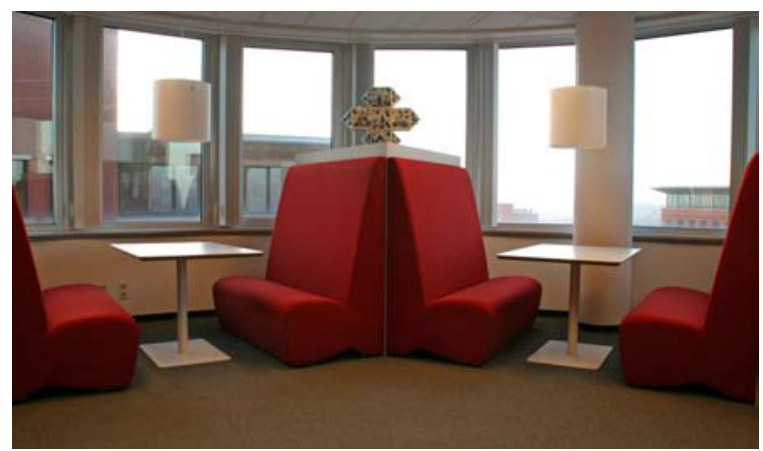

Fig 2. New is also a lounge area, where workers can meet.

Additionally, a case control study was done in a company where the interior of one floor of the building was changed into an area where no owned desks are found and where people could work from home. One group of employees consisting of two depart- ments started working on this floor and another group (the controls) continued to work in their traditional environment. The changed floor consisted of open areas, lounge areas, one person concentration rooms, various meetings rooms, lounge areas and two person rooms (see Figure 1 and 2). On a working day participants were able to choose a work station fitting to their task. The subjects received active RFID tags to measure their position in the old and new situation and to measure which percentage of the office floor was used during the day. Before and after the change to the new floor a questionnaire was given to the control and test group with questions regarding experienced productivity and health. 133 subjects were asked to complete the questionnaires in the old and new situation and multilevel analysis was performed to check significant differences $(\mathrm{P}<0.05)$ between the old and new way of work.

\section{Results: national data}

11,487 male and 12,301 female (total 23,788) completed the national questionnaire on the work and working conditions in 2010 in the Netherlands (response rate $30 \%$ ). The average hours per day VDU work in the Netherlands in 2010 based on this sample is 3.78 hours/day including working at home, with a laptop or notebook. This is higher in the group between 25-54 year old (4.2 hours/day) than in groups of other ages. The sector in the Netherlands working population where VDU work is highest is the financial service industry (6.38 hours/day) and it is lowest in agriculture/fishing industry (1.21 hours/day). In education work it is 3,73 hours/day, close to the average of the Netherlands.

In table 1 it is shown that $15.2 \%$ of the population is doing computer work at another location than the office or at the location of the client. This percentage is lower among female workers, among agriculture workers and in the hospitality industry. It is higher in the financial service industry, in the business service industry and public administration.

Table 1 also shows that $18 \%$ is not satisfied on the freedom they have in defining their own work time, which does not seem to be high. More than $80 \%$ is satisfied. Table 3 shows that $48 \%$ sees 'defining your own working time' as important and $24 \%$ as very important. In the financial service industry the group very satisfied is relatively larger and in the construction industry the group very satisfied with the freedom in working time is lower, which makes sense as in the financial service 
Table 1. Percentage of the Netherlands population teleworking and that is satisfied on the freedom to choose their own working times.

\begin{tabular}{|c|c|c|c|c|c|c|c|c|}
\hline & & & \multicolumn{6}{|c|}{ satisfied on deciding on your own working time } \\
\hline & \multicolumn{2}{|c|}{ telework } & \multicolumn{2}{|c|}{ not satisfied } & \multicolumn{2}{|c|}{ satisfied } & \multicolumn{2}{|c|}{ very satisfied } \\
\hline & $\%$ & $d \geq 0.20$ & $\%$ & $d \geq 0.20$ & $\%$ & $d \geq 0.20$ & $\%$ & $d \geq 0.20$ \\
\hline total & 15.2 & & 18.2 & & 59.1 & & 22.7 & \\
\hline male & 17.0 & & 18.6 & & 59.1 & & 22.3 & \\
\hline female & 13.0 & lower & 17.7 & & 59.1 & & 23.1 & \\
\hline $15-24$ year & 8.5 & & 21.6 & & 55.3 & & 23.1 & \\
\hline $25-54$ year & 16.8 & & 18.1 & & 58.9 & & 23.0 & \\
\hline $55-64$ year & 14.1 & & 15.4 & & 64.3 & & 20.3 & \\
\hline agriculture/fishing & 6.8 & lower & 12.3 & & 66.1 & & 21.7 & \\
\hline manufacturing & 11.3 & & 21.4 & & 59.3 & & 19.3 & \\
\hline construction & 9.1 & & 18.0 & & 67.6 & & 14.4 & lower \\
\hline trade & 9.9 & & 21.0 & & 59.3 & & 19.7 & \\
\hline hospitality & 5.1 & lower & 20.2 & & 58.1 & & 21.7 & \\
\hline transport/communication & 13.4 & & 24.7 & & 56.1 & & 19.3 & \\
\hline financial service & 27.3 & higher & 14.1 & & 53.6 & & 32.3 & higher \\
\hline business service & 25.1 & higher & 16.1 & & 55.0 & & 28.8 & \\
\hline public administration & 15.5 & & 11.5 & & 58.9 & & 29.6 & \\
\hline education & 21.9 & higher & 19.0 & & 59.5 & & 21.5 & \\
\hline healthcare & 10.8 & & 18.0 & & 63.5 & & 18.5 & \\
\hline culture and other services & 17.4 & & 14.6 & & 57.0 & & 28.5 & \\
\hline
\end{tabular}

Table 2 Percentage of the Netherlands population that is satisfied on the freedom to work at home.

\begin{tabular}{|l|c|c|c|c|c|c|}
\hline & \multicolumn{5}{c}{ satisfied on the possibility to work at home } \\
\hline & not satisfied & \multicolumn{2}{c|}{ satisfied } & \multicolumn{2}{c|}{ very satisfied } \\
\hline & $\%$ & $\mathrm{~d} \geq 0.20$ & $\%$ & $\mathrm{~d} \geq 0.20$ & $\%$ & $\mathrm{~d} \geq 0.20$ \\
\hline total & 27.0 & & 57.4 & & 15.6 & \\
\hline male & 27.0 & & 56.9 & & 16.1 & \\
\hline female & 26.9 & & 58.0 & & 15.1 & \\
\hline $15-24$ year & 31.5 & & 54.7 & & 13.8 & \\
\hline $25-54$ year & 26.8 & & 57.0 & & 16.3 & \\
\hline $55-64$ year & 22.8 & & 62.6 & 14.5 & \\
\hline agriculture/fishing & 21.9 & & 64.7 & & 13.4 & \\
\hline manufacturing & 31.5 & & 55.5 & & 13.0 & \\
\hline construction & 24.1 & & 65.1 & & 10.8 & \\
\hline trade & 28.5 & & 57.6 & & 13.8 & \\
\hline hospitality & 32.8 & & 54.1 & & 13.2 & \\
\hline transport/communication & 35.2 & & 49.8 & & 15.0 & \\
\hline financial service & 24.3 & & 51.0 & 24.7 & higher \\
\hline business service & 25.5 & & 53.9 & & 20.5 & \\
\hline public administration & 28.8 & & 56.4 & & 14.8 & \\
\hline education & 18.6 & lower & 64.8 & & 16.6 & \\
\hline healthcare & 25.5 & & 62.1 & & 12.3 & \\
\hline culture and other services & 22.0 & & 58.2 & & 19.9 & \\
\hline & & & & & & \\
\hline
\end{tabular}

Table 3. Percentage of the Dutch population that says it is important to have freedom in working time and to work at home.

\begin{tabular}{|c|c|c|c|c|c|c|c|c|c|c|c|c|}
\hline \multicolumn{7}{|c|}{ it is important to have the possibility to decide on your working time } & \multicolumn{6}{|c|}{ it is important to have the possibility to work at home } \\
\hline & not $\mathrm{i}$ & portant & & rtant & very & portant & \multicolumn{2}{|c|}{ not important } & \multicolumn{2}{|c|}{ important } & \multicolumn{2}{|c|}{ very important } \\
\hline & $\%$ & $\mathrm{~d} \geq 0.20$ & $\%$ & $\mathrm{~d} \geq 0.20$ & $\%$ & $\mathrm{~d} \geq 0.20$ & $\%$ & $\mathrm{~d} \geq 0.20$ & $\%$ & $\mathrm{~d} \geq 0.20$ & $\%$ & $\mathrm{~d} \geq 0.20$ \\
\hline total & 28.5 & & 47.7 & & 23.9 & & 62.3 & & 26.4 & & 11.4 & \\
\hline male & 33.7 & higher & 45.9 & & 20.5 & & 62.3 & & 26.6 & & 11.0 & \\
\hline female & 22.7 & lower & 49.7 & & 27.7 & & 62.2 & & 26.1 & & 11.7 & \\
\hline
\end{tabular}


industry it is easier to arrange freedom in working time than in the construction industry.

In table 2 it is shown that $27 \%$ is not satisfied on the freedom they have to work at home. Table 3 shows that $26 \%$ sees this as important and $11 \%$ as very important. In the financial service industry the group very satisfied is relatively large and in the education sector this group is lower.

\section{Results: case-control}

106 employees (of which 34 were in the controlgroup) completed the questionnaires. 47 both the preand posttest, 40 only the pretest and 19 only the posttest. One department had work which was more administrative of nature and the other was more communicative of nature. We were not allowed to mention the names of the departments, for this paper we call the departments: department adm and a department comm. The control group was a mix of these activities.

Work satisfaction: There was no significant effect on the questions related to work satisfaction between the old and new situation.

Health: There was no significant effect on the questions related to work satisfaction between the old and new situation.

Experienced productivity by communication: In this case there was a difference between the two departments. In the department comm all the questions showed a significant positive effect and in the adm department there was no significant effect shown. For example the question "how well is your office environment supporting you to work productive regarding the communication with your colleagues (give a number between 1 and 7, 7=high), showed a significant increase in the comm department, while the increase was not significant in adm.

Productivity by concentration: Again a difference was found between the two departments. In the department adm 3 out of the 5 questions related to productivity showed no significant reduction in concentration, while in the comm department no significant effect could be found. For example the question "how well is your office environment supporting you to work productive regarding the concentration (give a number between 1 and 7, 7=high), showed a significant reduction in the adm department, while in the comm a not significant increase is shown. The control group also showed an increase in productivity by concentration making the interpretation somewhat difficult.

Productivity by creativity: Regarding creativity again a difference was found between the two departments. In all answers related to creativity of the department adm no significant difference was found between the pre- and posttest, while in the comm department all three questions related to creativity showed a significant increase in creativity. For example the question "how well is your office environment supporting you to work productive regarding creativity (give a number between 1 and 7, $7=$ high), showed a significant increase in the comm department, while in the adm department no effects were found.

Comfort: The comfort was not significantly influenced in both departments.

Personalize the work environment: Regarding the personalizing of the work environment the significance was clear in both groups both questions on this aspects showed a significant reduction. For example the question "I can give my environment a personal touch (give a number between 1 and 7, 7=high)" the new situation scored significantly lower.

Representativeness and social climate: Regarding representativeness and social climate in both departments the same effect was seen. For instance, the question "how do you score the representativeness of your office environment (give a number between 1 and 7,7=high), a significant increase was seen.

The office use: the RFID data show that the office is still too large. For instance $30 \%$ of the meeting room space is empty all day in the new situation.

\section{Discussion}

The national data show that $15.2 \%$ of the Dutch population is doing computer work at another location than the office or at the location of the client. If we assume that this sample is representative for the Dutch population, more than 1 Million people in the Netherlands would actually work according to the new way of work in 2010. It is especially seen -as expected- in the financial, business and education sector. On the other hand as the Netherlands is a service industry country a larger group could be expected as well. The expectation is that this population will grow. There is for instance a Dutch national initiative by the government and the important 50 Dutch companies to introduce new way of working to reduce the traffic jams. More freedom in working times and working at home could reduce the number of 
people travelling in rush hours and thereby reduce traffic jams.

$27 \%$ of the Dutch working population is not satisfied about the possibility to work at home, which means that there is not so much need, which could influence the easiness of implementing new ways of work.

The number of workers who think that it is important to plan your own working time is around $71 \%$, which is probably more than what is possible now. Leaving space for improvement at national level.

The case-control study shows what has been reported in the literature before. Becker and Sims [1], Hengst et al. [3] and Vos and Van der Voordt [6] show that approximately $20 \%$ of employees working in combioffices do not like the not-owned desks. They miss the opportunity to personalize the work environment. People complain about a lack of privacy and poor facilitating of work requiring concentration. Also, in our study lack of concentration areas and the lack of personalizing the environment is mentioned. The fact that creativity is stimulated and the improvement of the representativeness in this study is found in other studies as well. According to Vos \& van der Voordt [6] is an open space a possible stimulator for interaction, meetings and creative group processes. The important improvement mentioned by the participants in this study was the representativeness. However, in implementing new ways of work care should be taken to the find a way to personalize the work environment and to make con- centration work possible. Of course working at home has opportunities for personalizing the environment there, but still the majority of the working time is spend in the office.

This study affirms effects of introducing new ways of work mentioned in the literature: the improved experienced productivity by communication and representativeness of the office interior are improved and the attention that is needed for workers that need concentration space and need to personalize their work environment. In implementing new ways of work these issues need attention.

\section{References}

[1] F. Becker and W. Sims, Offices That Work. International Workpace Studies program, University Ithaca, New York, 2001

[2] J. Cohen, Statistical power analysis for the behavioral sciences. Academic press, New York, 1977.

[3] M. den Hengst, J. de Leede, M.P. de Looze, F. Krause and K. Kraan, Working on distance, virtual teams and mobile work (in Dutch) TNO, Hoofddorp, 2008.

[4] L. Koppes, E. de Vroome, M. Mol, B. Janssen and S. van der Bossche, De nationale enquête arbeidsomstandigheden 2010. TNO, Hoofddorp, 2011.

[5] S.Y. Lee and J.L. Brand, Effects of control over office workspace on perceptions of the work environment and work outcomes. J. of Environmental Psychology 25 (2005), 323-333.

[6] P. Vos and Th. van der Voordt, Tomorrow's office through today's eyes: effects of office innovation in the working environment, J. of Corporate Real Estate 4 (2002), 48-65. 